\title{
Research Regarding the Assesment of the Coverage Degree for Phytosanitary Treatments Using Different Types of Nozzles
}

\author{
Ioan DROCAȘ*, Ovidiu MARIAN, Sorin STĂNILĂ, Ovidiu RANTA, Adrian MOLNAR \\ Faculty of Agriculture, UASMV Cluj-Napoca, Calea Mănăștur 3-5, Cluj-Napoca, Romania; \\ * corresponding author: drocas_i@yahoo.fr
}

Bulletin USAMV series Agriculture 71(2)/2014

Print ISSN 1843-5246; Electronic ISSN 1843-5386

DOI 10.15835/buasvmcn-agr: 10890

\begin{abstract}
Increased coverage when spraying, especially using contact substances, leads to higher efficiency and crops. Conventional nozzles, where the droplets move parallel to the stem of the plant ensures a good covering of the horizontal and inclined parts of plants, the vertical parts (strain) the deposit of the solution particles is lower and thus the coverage is inadequate. To remove this shortcoming, firms constructed nozzles with jet angle (symmetric or asymmetric), which provide good coverage also on the vertical parts of the plant. Experimental tests conducted with two types of nozzles aimed the coverage assessment of horizontal and vertical parts of the plant using conventional and double jet nozzles. Evaluation of coverage was made using water sensitive paper and the MATHCAD program, which determines the area covered. After processing and interpreting the results, experimental data revealed that using the double jet nozzles an increased coverage of vertical parts is assured, maintaining good coverage onto the horizontal parts.
\end{abstract}

Keywords: Coverage, spraying machine, types of nozzles, MATHCAD, water sensitive paper

\section{INTRODUCTION}

Pesticides are the main means of controlling weeds, pests and diseases of crops, but they should be used more wisely to reduce environmental pollution and residues in food. Lower remanence modern pesticides are biodegradable, they are more active and selective, but in order to obtain an effective treatment the application methods need to be upgraded, since the application influences the degree of environment pollution. It is known that, in addition to proper plant protection substances, strict adherence to the period of their application, machines and equipment for plant protection or spray quality can influence decisively the effectiveness of phytosanitary treatments. Weeds, diseases and pests control under field conditions requires correlating mechanical (machine), organizational and methodological factors. The control effect is optimal only when it ensures uniform coverage of plants with pesticides and drift and evaporation losses are minimal. The combination of two elements: the machine and application system, depending on specific conditions is the key for applying the minimum amount of chemical with maximum efficiency. Improvement of spraying machines is a permanent issue for building factories and it covers not only the automation of operations by introducing electronics, but also ensure adequate spray thus to ensure the best possible coverage of all parts of the plant.

It is known that dicotyledonous have broadleaved arranged horizontally, which allows for better retention of the drops, as opposed to the monocotyledonous grasses, in particular, with narrow leaves, upright stem and thus intercept and retain less solution, particularly when the jet is perpendicular to the ground. In order to ensure better coverage of monocotyledonous with solution and in particular the vertical strains, nozzle manufacturers developed nozzles with the 
double-jet, which is inclined with respect to the vertical plane at an angle. This leads to a better penetration of jet spraying solution between plants and ensure better coverage for stems that are upright.

The main objectives of this paper was to determine the coverage of plants with drops of solution using different types of nozzles. The nozzles were made by four important firms in the field.

\section{MATHERIAL AND METHODS}

For experimental tests the aggregate used was U-683 tractor unit and the EEP-600M [1] implement, a spraying machine which corresponds to European standards required. The spraying machine was equipped on all four types of nozzles, with different technical data, but with the same flow.

The nozzle D1 (Figure 1) is a plastic conventional nozzle with a lenticular spray pattern, manufactured by LECHLER, 120-04 LU type.

D2 nozzle (fig. 1) is made by the same company LECHLER, with a symmetrical double-jet pattern, type DF, 120-04, made of stainless steel.

Nozzle D3 (Figure 1) is AGROTOP Hispeed TD110-04 type, with double asymmetric jet pattern used for treatments at high speed. The angle of the jet is greater at the back $\left(50^{\circ}\right)$ and lower in the front $\left(10^{\circ}\right)$.
The nozzle D4 (Figure 1) is TTJ-type 110-04, double symmetrical jet nozzle made of plastic material, with the angle of the jets $15^{\circ}$.

All the four nozzles were at the same pressure and the same flow rate that is $1.5 \mathrm{l} / \mathrm{min}$ at a pressure of 2.8 bar. During experimental tests worked 3 bar pressure, resulting in a flow rate of 1.6 litters / min.

In order to determine the degree of coverage in horizontal and vertical planes were manufactured mounts (fig. 2). Water sensitive paper was pasted horizontally and vertically at the front and at the back.

Before each test the distance between boom and paper holder was adjusted to the height of 50 $\mathrm{cm}$, the working speed was $10.8 \mathrm{~km} / \mathrm{h}$, to provide a rate of $200 \mathrm{l} / \mathrm{ha}$.

For each type of nozzle three repetitions were made.

After experimental tests, samples of water sensitive paper prints were scanned and then using a program MATHCAD [2] which assesses the area covered, the coverage could be estimated.

\section{RESULTS AND DISCUSSION}

The samples scanned for the four nozzles are shown in the table 1 and coverage provided after evaluation using MATHCAD program are listed in figure 3.

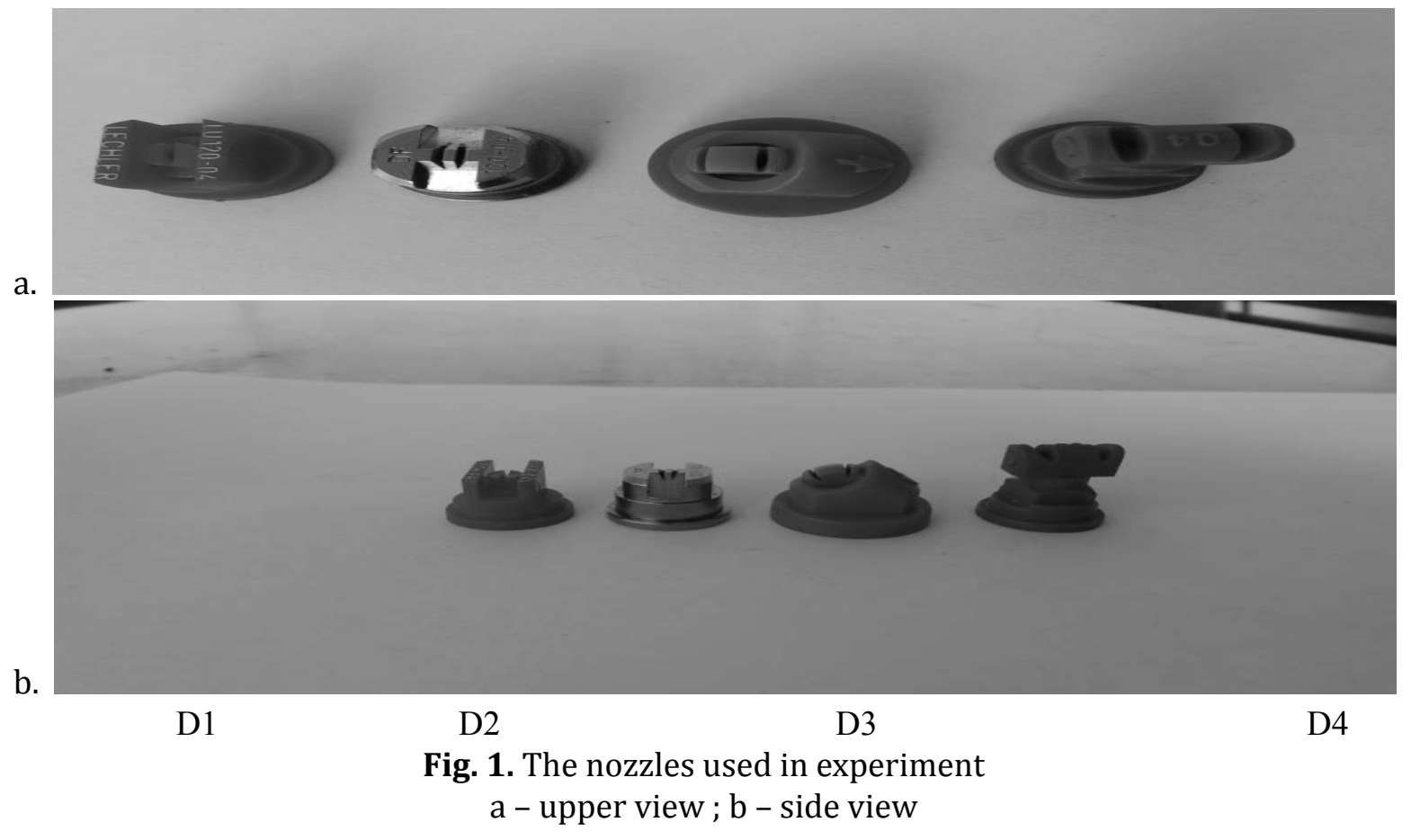



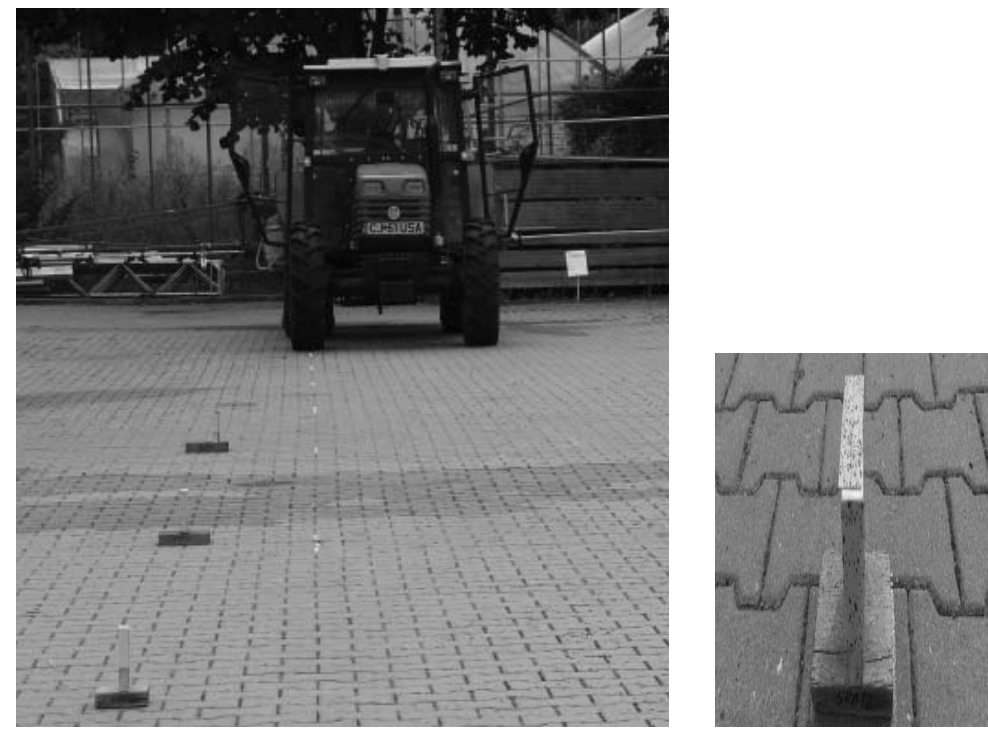

Fig. 2. U-683 + EEP-600ME aggregate and the water sensitive paper mounts

From image analysis in Table no. 1 and the data in Figure 3 can be seen following:

- nozzle D1, the conventional one, with a classic lenticular pattern achieved good coverage of the horizontal part (51.2\%) and especially the vertical posterior side had a lower degree of coverage $(2.09 \%)$;

- nozzle number 2 has double symmetrically jet and a greater angle between the two jets. It provides very good coverage in the horizontal $(52.28 \%)$ and the vertical plane $(49.64 \%)$, but lower on the vertical back (4.27\%);

- nozzle D3 has asymmetric double jet, higher angle at the back. It provides the best coverage of all the nozzles at the rear vertical $(6.25 \%)$ due to higher angle, but the front vertical and horizontal coverage is less than symmetric jet nozzle D2;

- nozzle number 4 is a symmetric double jet nozzle, lower angle between jets ensure good coverage of the horizontal and vertical front plane (36.02\% and $29.22 \%$ ), but on the rear upright provides the lowest coverage of all the nozzles $(1.71 \%)$.

To highlight the coverage achieved by the four types of nozzles a graph was done (Fig. 3).

It can be seen from the analysis of the graph as the best coverage with drops on the horizontal nozzle is provided by D2 followed by D1 nozzle. On the vertical the best coverage is provided by nozzles D2 and D4. The rear vertical part is better covered by D3

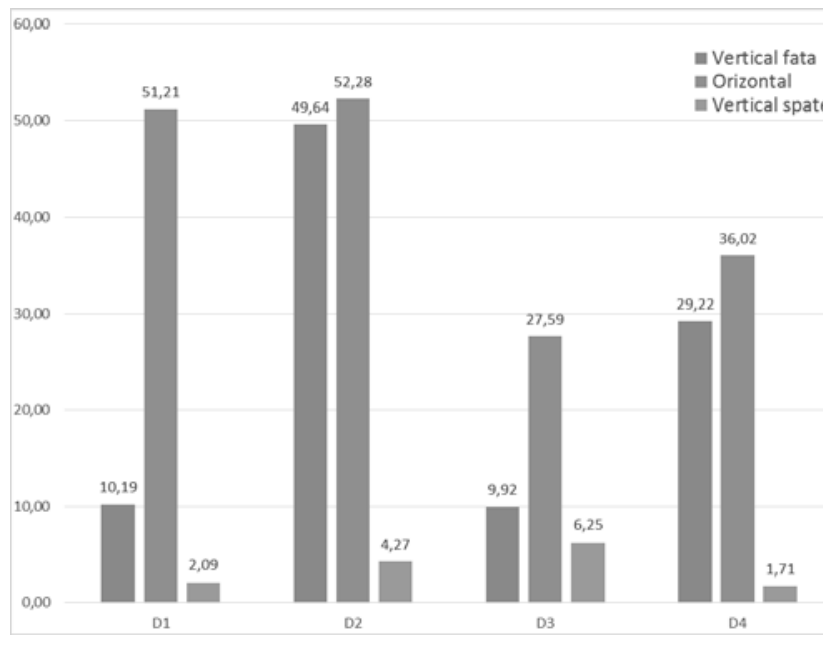

Fig. 3. Estimation of the coverage degree for the four nozzles

\section{CONCLUSIONS}

Analyzing data and charts resulting from experimental tests, the following conclusions can be drawn:

- to ensure good coverage, the type of nozzle will take into account the morphology of the plant, meaning that plants with several parts placed upright and narrow leaves (monocots) will be better covered by solution using doublejet nozzles. For broad-leafed plants, located horizontally or inclined, the jet nozzles may be used simply perpendicular to the ground ; 
Tab. 1. Water sensitive prints after scan

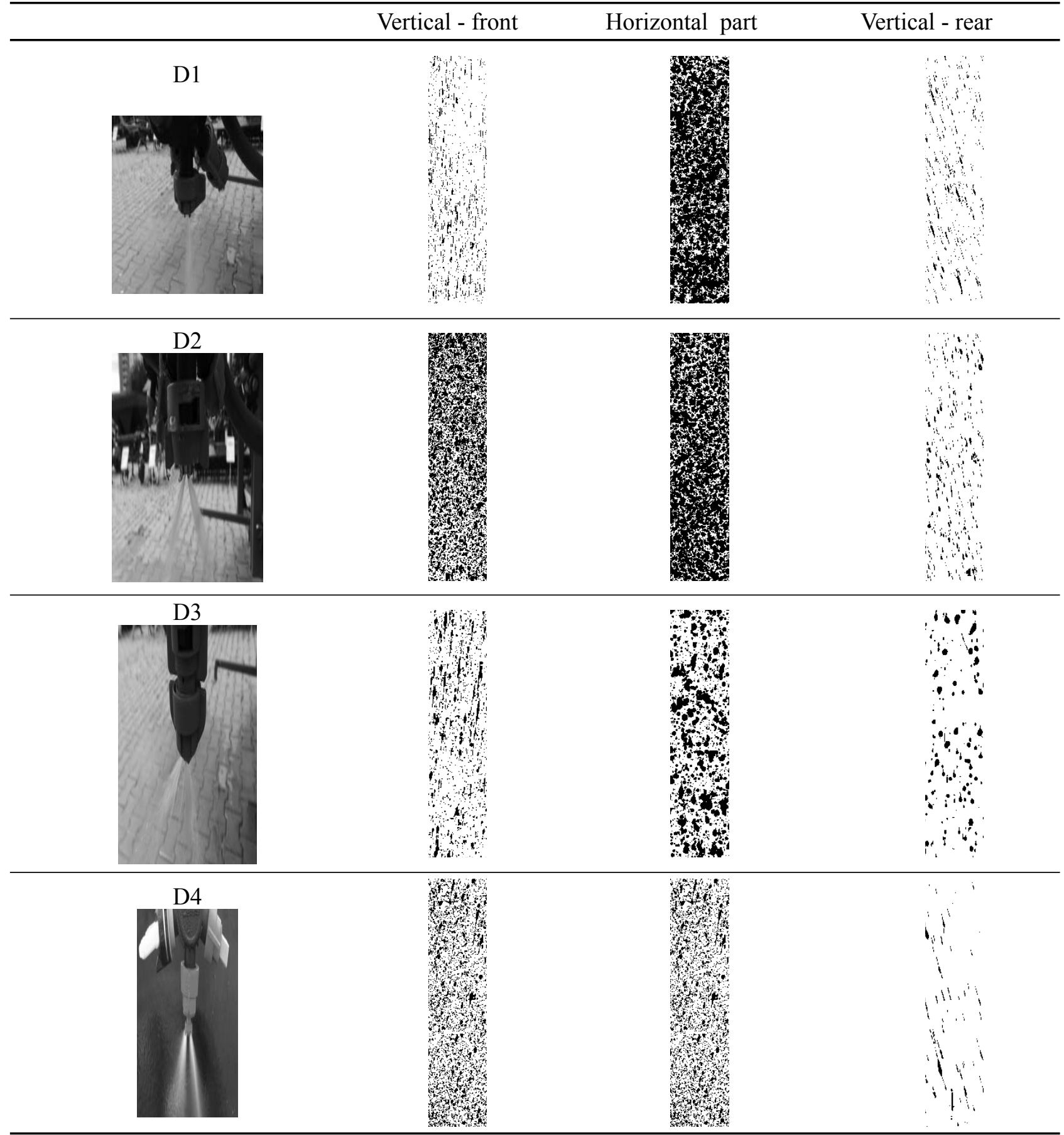

- the best coverage vertical and horizontal, is achieved using the double jet 120-04 DFsymmetrical ;

- on the vertical plane in the rear, nozzle TD110-04 provides the best coverage;

- simple jet nozzles and double jet with smaller angle between jets, had the best coverage for the vertical posterior plane.

\section{REFERENCES}

1. Drocaș, I., O. Marian, O. Ranta, A. Molnar-Irimie, S. Stănilă, Modernization of the EEP-600 spraying machines in order to comply with the European Rules, INMATEH, 2008.

2. Roș, V., M. Ghereș, Method and program for evaluation of spray deposit, Bulletin USAMV, Agriculture, Vol.61, Nr.1/2008, p.229-234, ISSN 1454-2382.

3. 3. www syngenta.com 